
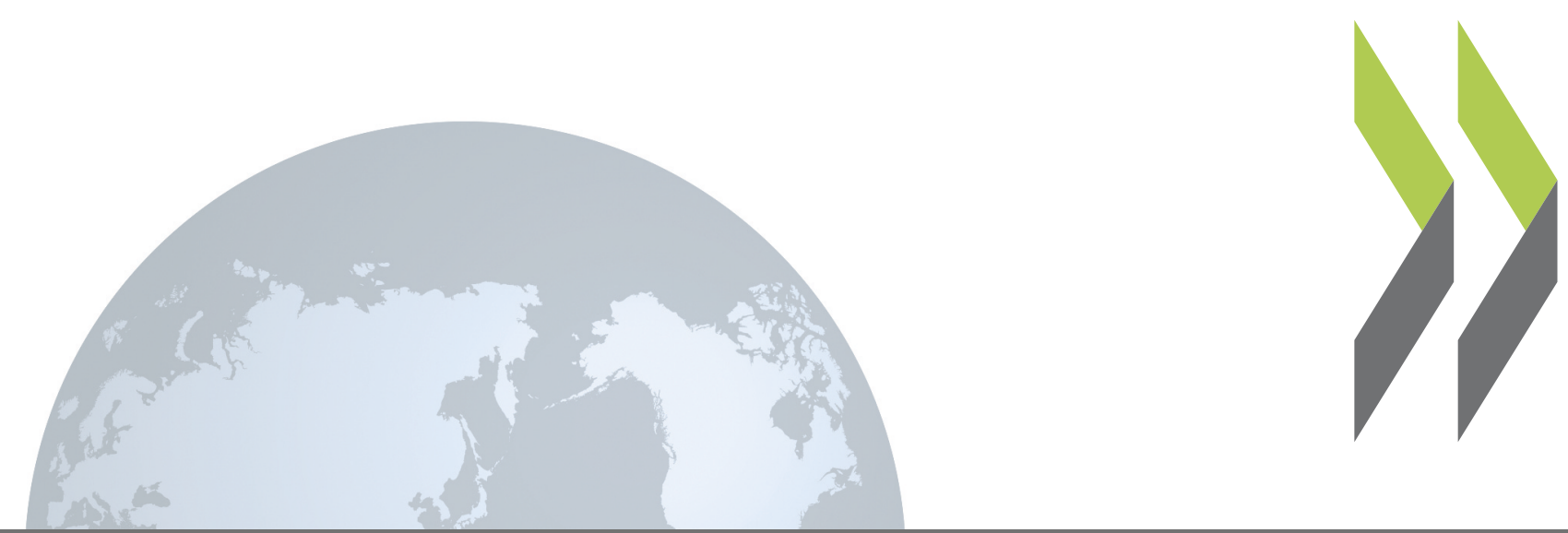

SIGMA Papers No. 7

\title{
The Audit of Secret and Politically Sensitive
} Subjects: Comparative Audit OECD Practices 
THE AUDIT OF SECRET AND POLITICALLY SENSITIVE SUBJECTS:

COMPARATIVE AUDIT PRACTICES

SIGMA PAPERS: No. 7

ORGANISATION FOR ECONOMIC CO-OPERATION AND DEVELOPMENT

Paris 1996

32995

Document complet disponible sur OLIS dans son format d'origine

Complete document available on OLIS in its original format 



\section{The SIGMA Programme}

SIGMA -- Support for Improvement in Governance and Management in Central and Eastern European Countries -- is a joint initiative of the OECD Centre for Co-operation with the Economies in Transition and EC/PHARE, mainly financed by EC/PHARE. The OECD and several OECD Member countries also provide resources. SIGMA assists public administration reform efforts in Central and Eastern Europe.

The OECD -- Organisation for Economic Co-operation and Development -- is an intergovernmental organisation of 27 democracies with advanced market economies. The Centre channels OECD advice and assistance over a wide range of economic issues to reforming countries in Central and Eastern Europe and the former Soviet Union. EC/PHARE provides grant financing to support its partner countries in Central and Eastern Europe to the stage where they are ready to assume the obligations of membership of the European Union.

Established in 1992, SIGMA operates within the OECD's Public Management Service (PUMA). PUMA provides information and expert analysis on public management to policy-makers in OECD Member countries, and facilitates contact and exchange of experience amongst public sector managers. Through PUMA, SIGMA offers eleven countries a wealth of technical knowledge accumulated over many years of study and action.

Participating governments and the SIGMA Secretariat collaborate in a flexible manner to establish work programmes designed to strengthen capacities for improving governance in line with each government's priorities and SIGMA's mission. The initiative relies on a network of experienced public administrators to provide counselling services and comparative analysis among different management systems. SIGMA also works closely with other international donors promoting administrative reform and democratic development.

Throughout its work, SIGMA places a high priority on facilitating co-operation among governments. This includes providing logistical support to the formation of networks of public administration practitioners in Central and Eastern Europe, and between these practitioners and their counterparts in OECD Member countries.

SIGMA's activities are divided into six areas: Reform of Public Institutions, Management of Policy-making, Expenditure Management, Management of the Public Service, Administrative Oversight, and Information Services.

\section{Copyright OECD, 1996}

Applications for permission to reproduce or translate all or part of this material should be made to: Head of Publications Service, OECD, 2, rue André-Pascal, 75775 Paris Cedex 16, France.

Views expressed in this publication do not represent official views of the Commission, OECD Member countries, or the central and eastern European countries participating in the Programme. 



\title{
Foreword
}

In all countries of Central and Eastern Europe, institutions for independent parliamentary audit have been set up since 1989. These Supreme Audit Institutions (SAIs) have been established in some cases by totally new legislation, in other cases by amendment of the mandates of existing institutions, in still others by reinstatement of institutional traditions from the pre-communist period.

As could be expected, the implementation of the new practices involves continuous learning and problem solving by all affected parties. The roles of the SAIs, the roles of other control bodies and, especially, the development of productive working relationships between administration and auditor continue to demand attention.

Nowhere in the world is the relationship between auditor and auditee an easy one. By definition, their respective interests generate the potential for conflict. Within government administrations, those activities which are secret or politically sensitive are most likely to expect exemption from, or special treatment in, the conduct and reporting of outside audits.

In response to requests from several SAIs, SIGMA has undertaken a comparison of audit practices in this area, the results of which are summarised in this paper. We are grateful to the SAIs of France, Germany, the Netherlands and the United Kingdom for their co-operation in providing information for this study.

As always, neither SIGMA nor the author intend anything in this paper to be taken directly as a model; rather it is intended to present examples of practices and methods among which each country in Central and Eastern Europe may find ideas useful for adaptation within the context of their particular administrative cultures.

The author of this paper, Mr. Roelof Voormeulen, was Executive Director of the Control Auditing Department in the Ministry of Finance of the Netherlands and Chairman of the Interdepartmental Council on Auditing. He is past President of the Public Sector Committee of the International Federation of Accountants. This SIGMA Paper is also available in French under the title "L'audit des domaines secrets et politiquement sensibles : méthodes comparées".

Lawrence J O'Toole

Counsellor for Expenditure Management

May 1996

\author{
SIGMA-OECD \\ 2, rue André-Pascal \\ 75775 Paris Cedex 16, France \\ Tel (33.1) 45.24.13.11 \\ Fax (33.1) 45.24.13.00 \\ e-mail: sigma.info@ oecd.org \\ http://www.oecd.org/puma/sigmaweb
}


Table of Contents

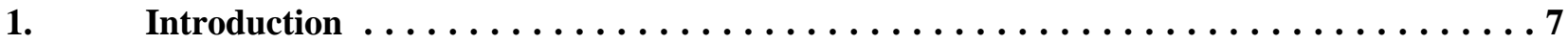

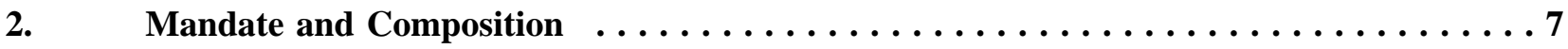

3. General Aspects of Secret and Politically Sensitive Subjects $\ldots \ldots \ldots \ldots \ldots \ldots \ldots$

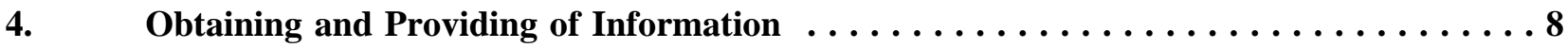

5. Some Specific Practices with Respect to Secret or Politically Sensitive Subjects ....... 9

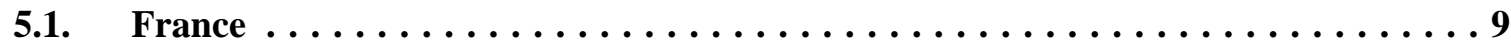

5.1.1. Audit of the Secret Services . . . . . . . . . . . . . . . . 9

5.1.2. Audit of the Expenditure of the President of the Republic ........ 9

5.1.3. Audit of the Expenditure of the Parliament $\ldots \ldots \ldots \ldots \ldots \ldots$

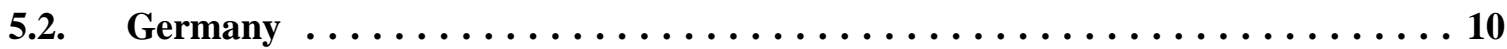

5.2.1. Audit of Secret Defence Expenditure $\ldots \ldots \ldots \ldots \ldots \ldots \ldots \ldots \ldots$

5.2.2. Audit of Secret Service Expenditure ................ 10

5.2.3. Audit by the BRH President in persona $\ldots \ldots \ldots \ldots \ldots \ldots \ldots$

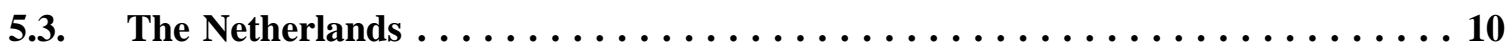

5.3.1. Audit of the Intelligence and Security Services . . . . . . . . 10

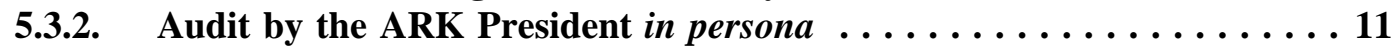

5.3.3. Audit of the Expenditure of the Crown $\ldots \ldots \ldots \ldots \ldots \ldots 1$

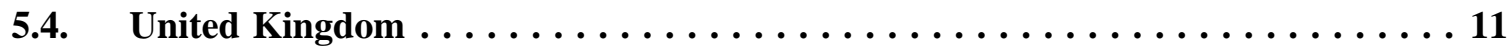

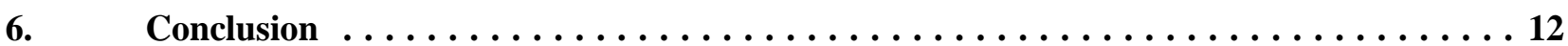


This paper is the result of a comparison of the audit practices with respect to the audit of secret and politically sensitive subjects by the Supreme Audit Institutions (SAI's) of France, Germany, the Netherlands and the United Kingdom. Not only do the practices differ but the mandate and composition of the SAI's themselves are also different. This also influences the way the SAI's operate.

\section{Mandate and Composition}

It would justify a separate study to analyse all the differences between the four SAI's. Therefore only the differences which are important to understand the different ways of conducting the audit of secret and politically sensitive subjects are highlighted.

The French Cour des Comptes (CdC) is a court of law, which consists of over two hundred magistrates, who are actively involved in the audits. The magistrates form seven chambers. Each chamber deals with a specific part of the French administration, for example a chamber might handle two ministries and the public enterprises controlled by them. Inside this sector of the administration the mandate is very broad. There are no restrictions whatsoever on the type of audit the $\mathrm{CdC}$ wants to conduct. Each year the $\mathrm{CdC}$ reports to Parliament about the execution of the budget. The $\mathrm{CdC}$ does not give a formal audit opinion on the yearly accounts, and is free to include in the report whatever it chooses to publish.

The German Bundesrechnungshof (BRH) is a supreme federal authority. The 59 members form small chambers (kollegium) of 2 or 3 members, which deal with the result of the various audits. The contents of the yearly report to Parliament is decided by the meeting of the 16 most senior members (grosse senat). The BRH does not give a formal audit opinion on the yearly accounts. Its mandate though is very broad and includes the aspects of regularity, compliance and performance. The President of the BRH serves ex officio as Federal Commissioner for Efficiency in Public Administration.

In the Netherlands the Algemene Rekenkamer (ARK) is a High Council of State, which has 3 members. Their mandate includes the aspects of regularity, compliance and performance. The ARK reports yearly to Parliament. The contents of the report is decided by the members. The report contains a formal audit opinion on the accounts.

In the United Kingdom the Comptroller and Auditor General (C\&AG) is responsible for the audit of government affairs. The staff is known as the National Audit Office. In contrast to the French, German and Dutch situation there is no shared responsibility. In the United Kingdom one person is responsible and takes the ultimate decisions. The C\&AG reports each year to Parliament and the report contains a formal audit opinion on the accounts. The C\&AG's mandate does not include the investigation of government policy.

All SAI's do publish interim reports. Parliament could either have asked for such a report or the report is published under the authority of the SAI itself. The interim reports are normally confined to a single government organisation or to a single matter of government policy or administration.

\section{General Aspects of Secret and Politically Sensitive Subjects}

Whether a subject is labelled secret is decided by Parliament. In the UK this may be as part of the founding legislation. In other countries some lines in the annual Budget are labelled secret with the consent of Parliament. For example, the operating funds of the secret services may be labelled secret while 
the personnel and normal operational costs are part of the non-secret budget of one of the ministries. For the auditor this may mean he cannot obtain any information about the use of the secret funds, while he has full access to the information about the other activities of the organisation. It is self evident the auditor has to have appropriate security clearance in these cases and has to be extremely careful about what information he provides to whom.

Normally secret funds will be used by government organisations which can also be considered politically sensitive. Drawing a line between secret subjects on the one hand and politically sensitive ones on the other hand may therefore be very difficult. Of course there are some subjects which are "only" politically sensitive. For instance, in most countries the expenses of the head of state are considered as such. In these cases the auditor has to act with reticence but is in principle allowed full access to the information he needs. For the purpose of this paper subjects are considered as secret only if Parliament has labelled them as such.

\section{Obtaining and Providing of Information}

Most government organisations, which deal with secret or politically sensitive subjects can be expected to try to restrain the information they provide their auditors. Normally that is not because they do not want to be accountable, but because they are afraid of a breach of security or confidentiality by the auditor. To improve the willingness of the auditee to provide the auditor with the information he needs the auditor has first of all to guarantee his auditee he will use the information with proper discretion and the secret or sensitive information will not be released outside the auditor's organisation. Depending on the level of secrecy the auditor has to take appropriate measures to safeguard the information from unauthorised access. These measures may even include secluded rooms, a specific secret registry, a tapping-proof discussion room and the installation of Tempest-proof copying machines and computers. Furthermore any auditor involved in classified audit issues has to be regularly checked in strict accordance with the applicable regulations so as to maintain a high standard of personnel security.

In short, to obtain the information he needs the auditor has to live up to the same security standards as are applicable to his auditee. This principle applies whether we speak of secret subjects or merely sensitive ones, although the standards are different .

Safeguarding a secret is easier if the number of people that know about it is kept to a minimum. So, especially in SAI's where normally the results of an audit are discussed in larger groups there are some special practices with respect to secret and politically sensitive subjects. In the extreme this might be only one person -- very often the president of the SAI -- auditing the subject and reporting to one other person (the Head of State or the responsible minister) or a very small committee of absolutely trustworthy people, such as very senior members of parliament.

A secret report can have different forms. Which form should be chosen depends on the level of secrecy that has to be safeguarded.

The most strict form is an oral report by the auditor to just one authorised person, delivered in absolutely secure surroundings. The oral report can be supported by a "one copy only written report" which is handed over in person. Sometimes this written report is destroyed at the end of the meeting in the presence of the auditor.

In some cases the auditor will have to report not to one person but to a small group of authorised officials. In this case it can either be solely an oral report or an oral report supported by a written report, the copies of which are restricted to the number of people in the group and are handed over in person. In 
this case it is perhaps even more desirable to destroy the copies of the written report at the end of the meeting.

Another, less strict, possibility is to issue a limited number of copies of a written report which are delivered by courier, where the copies are individualised and the addressee has to sign for delivery.

Sometimes there is a public version of a report and a confidential version which provides the information that has to be kept secret. In a variant of this method, the confidential information is provided orally and not written down.

\section{Some Specific Practices with Respect to Secret or Politically Sensitive Subjects}

\subsection{France}

\subsubsection{Audit of the Secret Services}

The Prime Minister's office has a budgetline "secret funds". The Prime Minister has free disposal of this fund. As far as the money is used as special funding for the intelligence services it is audited by a special committee of two members of the $\mathrm{CdC}$ and one employee of the Inspection General of the Ministry of Finance. The committee reports confidentially to the Prime Minister himself in the form of a written report with only a single copy, supplemented with information delivered orally.

The normal organisational and personnel expenses of the secret services are included in the budgets of the ministries of Defence, Police and Foreign Affairs. These expenses are audited by the CdC and discussed in a chamber with a small number of members. The written report is confidential and is provided to a limited audience on a need-to-know basis.

\subsubsection{Audit of the Expenditure of the President of the Republic}

The expenses of the President are considered to be politically sensitive. The CdC determines whether the total amount spent is in accordance with the budget approved by Parliament. The details of the various expenses themselves are not audited.

Many of the costs of the Presidency are covered by the various ministries; for example, housing by the Ministry of Culture, security by the Ministry of Police, transport by the Ministries of Defence and Interior Affairs, state visits by the Foreign Ministry, etc. These costs are audited in the normal way.

\subsubsection{Audit of the Expenditure of the Parliament}

By tradition the expenditure of the Parliament is not audited. The CdC only determines whether the total is in accordance with the budget. There is a confidential budget advisory committee, which consists of eight members of Parliament and three members of the CdC. This committee advises the presidium of the Parliament about the budget for the next year. 


\subsection{Germany}

In 1969 Parliament amended the Constitution to establish the principle of full audit coverage of all fields of government activity. But, examinations into secret matters can be submitted to special procedures by statute. The German audit system has found the following solution: while audit itself is ensured, restrictions do apply to the number of auditors involved and to reporting.

\subsubsection{Audit of Secret Defence Expenditure}

The expenditure is fully audited. However a small number of highly sensitive data has to be omitted or information has to be generalised before reporting publicly. In some cases data is so closely interrelated that no distinction can be made between information that must be withheld and data that can be released. In these cases the defence project is secret as a whole, and the report -- labelled restricted, confidential, secret -- is issued only to a few designated and duly authorised officials.

\subsection{2. $\quad$ Audit of Secret Service Expenditure}

The federal budget sets out only the totals of the funds appropriated by Parliament to the three secret services. These budgets are discussed in detail by the confidential budget committee of five members of the parliamentary budget committee. The confidential committee communicates to the budget committee the totals to be provided by the federal budget. These budgetlines are approved without further discussion.

The auditors examine the secret services in a similar way as any other government agency. Their audit criteria are regularity, compliance and performance. However, the audit findings are only reported to the same confidential budget committee, the ministry responsible for the service and the ministry of finance.

\subsubsection{Audit by the BRH President in persona}

The secret and special purpose fund of the Foreign Ministry and the discretionary fund of the Federal Chancellor are audited by the BRH President in persona. He has to determine the funds are not spent on such activities as entertainment, or excess funding of programs provided for under other budget headings, or funding of programs that Parliament has rejected in its budget deliberations. The BRH President communicates his findings to the Permanent Secretary of the Foreign Ministry and to the Head of the Federal Chancellery. If he judges the findings to be of major parliamentary interest he may communicate them only to the presidents of the two chambers of Parliament, to the Federal Chancellor and the Federal Minister of Finance.

\subsection{The Netherlands}

\subsubsection{Audit of the Intelligence and Security Services}

The expenditure of the intelligence and security systems is part of the budget of the Ministries of Defence and Interior Affairs. As far as the budget headings are not labelled secret they are audited in the normal way. The reports however are restricted and distributed on a need-to-know basis, normally only to the Head of Service, the Secretary-General, the Minister and the members of the parliamentary permanent committee on intelligence and security. 


\subsubsection{Audit by the ARK President in persona}

Each budget heading that is labelled as secret has to be audited by the ARK President in persona. If he deems it necessary he reports his findings orally to the responsible Minister in person. The ARK President is not allowed to inform Parliament or his colleagues of the Council. The parliamentary permanent committee on the intelligence and security services, consisting of four members of Parliament, may be confidentially informed by the minister. This is done at the discretion of the Minister but he has an incentive to do so and thereby share the responsibility with them.

\subsubsection{Audit of the Expenditure of the Crown}

The expenses of the Crown are considered to be politically sensitive. By tradition the budget chapter with respect to the Crown is audited in a restricted way. That is to say, the private audit firm, employed by the Crown, provides a formal audit opinion, which is accepted by the ARK.

Many of the costs of the Crown are covered by the various ministries. For example, housing and transport by the Ministry of Interior Affairs, security by the Ministry of Defence, state visits by the Foreign Ministry, etc. These costs are audited in the normal way.

\subsection{United Kingdom}

The Comptroller and Auditor General of the United Kingdom has to provide a formal audit opinion on the yearly accounts. Until 1994 the C\&AG had full access to all government expenditure except the expenditure of the Security Service and the Secret Intelligence Service. The Public Accounts Committee (PAC) decided in 1879 that any services of a confidential nature should be charged to the Secret Service Vote and the C\&AG was not expected to audit this vote. As the C\&AG had to provide an audit opinion on all budget votes the secret vote was covered by a special certificate, which read

"I certify that the amounts shown in the above account to have been expended (and received) are supported by certificates from the responsible Ministers of the Crown"

With effect from 1 April 1994 the Intelligence Services Act has been amended. The budget heading for the Secret Services does not disclose the allocation of expenditure between the agencies but it shows a breakdown between running costs and capital expenditure.

Each of the agencies produces an account, which is audited by the C\&AG. These accounts are not published but drawn together into a consolidated appropriation account, which is presented to Parliament. The C\&AG certificates the consolidated account. Thus the C\&AG has full access to the details but this information does not leave his office.

The C\&AG now has full access to the information he needs for his audit. Only such things as the names of agents, the objectives of operations, etc. may be withheld from him.

The C\&AG does not disclose in reports to Parliament and/or the PAC any information which is highly sensitive on security grounds. In such circumstances he consults the Chairman of the Committee. The PAC has agreed that in these cases the Chairman makes the necessary enquiries and does not inform the full committee. 


\section{Conclusion}

The four countries examined in this paper are believed to offer a reasonable sample of the practices employed in most countries. Some general conclusions can be drawn from these findings.

i. Whether a subject is labelled secret has to be decided by Parliament, either by approving the founding legislation or by labelling some lines in the annual Budget as such. Normally secret funds will be used by government organisations which can also be considered politically sensitive. Drawing a line between secret subjects on the one hand and politically sensitive ones on the other hand may therefore by very difficult.

ii. If a subject is considered to "only" politically sensitive, as are the expenses of the head of state in most countries, the auditor has to act with reticence but is in principle allowed full access to the information he needs.

iii. A basic principle is that the auditor should live up to the same security standards as are applicable to his auditee. Depending on the level of secrecy the auditor has to take appropriate measures to safeguard the information from unauthorised access. These measures may even include secluded rooms, a specific secret registry, a tapping-proof discussion room and the installation of Tempest-proof copying machines and computers. Furthermore any auditor involved in classified audit issues has to be regularly checked in strict accordance with the applicable regulations to maintain a high standard of personnel security.

iv. In the case of subjects officially labelled secret by Parliament, the auditor should aim for full audit coverage, but be prepared to restrict the number of staff involved and restrict the distribution of his reports.

v. Restricting the number of staff involved in an audit may, in the extreme, mean only one person auditing the subject. The more people know about a secret audit issue, the more difficult it is to protect the information. Planning an audit of a secret subject therefore also means deciding on the minimum of staff that has to be involved. Consulting the auditee about this number is in most cases advisable.

vi. As stated before, the auditor must also be prepared to restrict the distribution of his reports. The more copies of a report are in existence the more difficult it is to protect the information.

Depending on the level of secrecy, the auditor can choose among the following formulae:

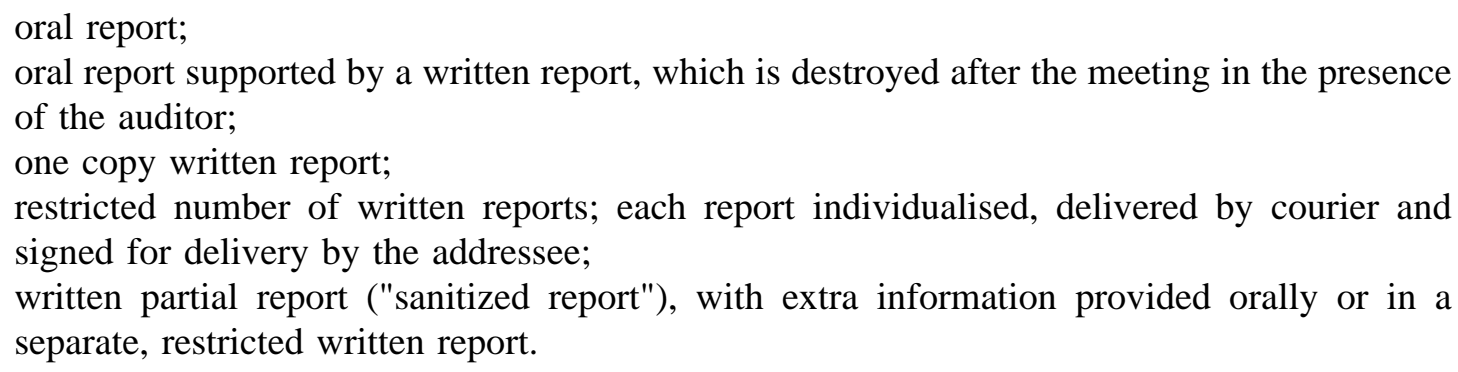

vii. The precise combination of measures suitable for a specific country, as clearly demonstrated by this paper, will vary to suit its traditions and administrative arrangements. Full consultation among the interested parties is recommended as a means of gaining consensus on appropriate practices. 